Rev. Elet. em Gestão, Educação e Tecnologia Ambiental (e-ISSN: 2236-1170)

\title{
O IMPACTO DA AGRICULTURA SOBRE O MEIO AMBIENTE
}

\author{
Rafael Mattos de Deus, Sonia Maria Cipriano Bakonyi \\ ${ }^{1}$ Biólogo - Graduado na Faculdade de Ciências, Universidade Estadual Paulista "Júlio de Mesquita Filho"; Pós- \\ graduado no curso de Especialização em Gestão Ambiental e Desenvolvimento Sustentável da FATEC Internacional- \\ Faculdade de Tecnologia Internacional. Contato: rafalives@gmail.com \\ ${ }^{1}$ Bióloga - Doutora em Geografia pela UFPR- Universidade Federal do Paraná; Professora dos Cursos de Pós- \\ Graduação em Saúde Pública e Meio Ambiente do Grupo Uninter; Membro do Comitê de Ética do Grupo Uninter; \\ Professora e Assistente de Coordenação da FEPAR - Faculdade Evangélica do Paraná na área de Saúde Ambiental.: \\ sbakonyi@grupouninter.com.br
}

\section{RESUMO}

O desenvolvimento da humanidade nos últimos tempos tem mudado o ambiente natural ao quais todos se inserem. Estas mudanças, em sua grande parte, são impactos sobre a fauna e a flora. Além das indústrias e da cidade, a agricultura também interfere nesta mudança, vê-se o crescimento intensivo e uso indiscriminados de agrotóxicos, do solo, da água, além dos desmatamentos e uso intensivo e prolongado de monoculturas - em que todos estes fatores prejudicam o meio ambiente, incluindo o próprio homem. Entretanto a tecnologia busca alternativa e mecanismos para auxiliar o desenvolvimento agrário sem prejudicar o ambiente, isto é o que propõe as leis e conferências para o desenvolvimento sustentável. Um exemplo é o uso de substâncias naturais para prevenir pragas em substituição dos agroquímicos que causam danos. A água, por exemplo, pode ser usada de uma forma mais racional com uso de irrigação ou fertirrigação por gotejamento, onde já foi comprovado uma grande economia de água e o desenvolvimento melhor das plantas em questão. Portanto este trabalho teve o objetivo de mostrar o papel da agricultura na decadência da sustentabilidade, mas também rever as tecnologias e alternativas existentes para que haja um desenvolvimento conjunto do ambiente e da agricultura.

Palavras-chave: impacto ambiental, alternativas, agricultura orgânica, meio ambiente

\section{ABSTRACT}

The development of humanity in recent times has changed the natural environment. These changes, for the most part, are impacts on fauna and flora. In addition to the industries and the city, these changes also have been affected by agriculture, there are the intensive growth and indiscriminate use of pesticides, of soil, of water, and of deforestation and intensive and prolonged monoculture - all these factors affect the environment, including man himself. However there are researches about alternative technology and ways to assist agricultural development without harming the environment, this is what the laws and conferences propose for sustainable development. An example is the use of natural substances to prevent pests, rather than agricultural chemicals. Water, for example, can be used with more rational or by drip irrigation, that shows a great saving of water and better development of the plants. Therefore this study aimed to show the role of agriculture in the decadence of sustainability, but also reviews the 


\section{Rev. Elet. em Gestão, Educação e Tecnologia Ambiental (e-ISSN: 2236-1170)}

existing technologies and alternatives to allow the development of both environment and agriculture.

Keywords: environmental impacts, alternatives, organic agriculture, environment

\section{INTRODUÇÃO}

O desmatamento para atividades agropastoris e a necessidade de evitar a reestruturação da floresta natural para, então, atingir o ápice da produção desejada, são as consequências de impactos ambientais causados diretamente pelas atividades agropecuárias. E para que não ocorra a tal reorganização natural do local, a agricultura se utiliza quase que totalmente, de materiais orgânicos e inorgânicos externos e tecnologias mecanizadas, assim a cultura é totalmente protegida em grandes áreas (RODRIGUES, 1999).

Em sua maioria, estas grandes áreas são monoculturas, que mudam significativamente o ambiente, tanto sua fauna quanto flora. Além disso, as monoculturas podem causar problemas pra si mesmos, como é o caso do milho em que as podridões das espigas e grãos ardidos são aumentadas na prática de monocultura (TRENTO; IRGANG; REIS, 2002).

Afora isto sempre houve um uso indiscriminado e demasiado de substâncias tóxicas (como fertilizantes, herbicidas e pesticidas) na agricultura, a partir daí há um decrescente índice de qualidade de vida das pessoas e um aniquilamento dos recursos ambientais (DOBSON, 1994; MARTELL, 1994).

Devido ao fato é necessário buscar alternativas para minimizar os impactos ambientais e não atrapalhar a economia, esse é o segredo da agricultura sustentável, a qual pode ser definida de tal forma:

\footnotetext{
"Agricultura sustentável é o manejo e a utilização do ecossistema agrícola, de modo a manter sua diversidade biológica, produtividade, capacidade regenerativa, vitalidade e habilidade de funcionamento, de maneira que possa preservar - agora e no futuro significantes funções ecológicas, econômicas e sociais na esfera local, nacional e global, e não cause danos em outros ecossistemas" (LEWANDOWSKI et al., 1999, citando a Conferência de Ministros Europeus de Meio Ambiente).
}

Mas para que haja e desenvolva a agricultura sustentável, é necessária a aplicação de Avaliação de Impacto Ambiental (AIA) sobre as atividades de manejo de culturas, por que ela envolve a produção intensiva com uso de tecnologias, não se importando em economizar (NEHER, 1992), e confere importância a conservação e recuperação da paisagem em si (BOWERS; HOPKINSON, 1994), ressaltando que a AIA favorece e sustenta ambas as partes.

Porter (1995) diz que não se pode abdicar para as atividades agropecuárias a aplicação da AIA ao seu desenvolvimento sustentável, por causa da interação da tecnologia - meio ambiente e sociedade, envolvendo os mais variados valores e propósitos, isto resulta em menores impactos.

O objetivo deste trabalho foi levantar o que se tem pesquisado e buscado como tecnologia alternativa, principalmente no setor agrário, pois o assunto carece no que diz respeito à abordagem, já que o impacto ambiental causado pelas indústrias e cidades está em maior evidência. 
Rev. Elet. em Gestão, Educação e Tecnologia Ambiental (e-ISSN: 2236-1170)

\section{MATERIAL E MÉTODOS}

Como trabalho teórico e com a finalidade de se levantar dados pré-estudados, este estudo utiliza a literatura disponível no meio científico. Portanto faz-se apenas o uso de uma revisão literária sobre o tema: a ação da agricultura sobre o meio ambiente.

\section{RESULTADOS E DISCUSSÃO}

\section{O impacto da agricultura sobre o meio ambiente}

Antes de tudo vale ressaltar o que o CONAMA, Resolução 001/86, define como impacto ambiental (BRASIL, 1986):

\footnotetext{
“(...) considera-se impacto ambiental qualquer alteração das propriedades físicas, químicas e biológicas do meio ambiente, causada por qualquer forma de matéria ou energia resultante das atividades que, direta ou indiretamente, afetam:

I - a saúde, a segurança e o bem-estar da população;

II - as atividades sociais e econômicas

III - a biota

IV - as condições estéticas e sanitárias do meio ambiente

V - a qualidade dos recursos ambientais"
}

Ao ver este panorama traçado pela resolução, então todas as atividades que o homem faz deve passar por este crivo, para que assim sejam analisados todos os aspectos e busquem alternativas que concorram para o meio ambiente. Portanto as atividades do setor agrário também devem ser examinadas detalhadamente.

Como exposto, a atividade agropecuária aparece como grande responsável pela degradação intensa das águas. As águas de muitos cursos hídricos, antes consideradas inalteráveis, chegaram ao limite, em que não se recomporão de forma natural. Muitas fontes naturais de água acabaram devido ao mau uso e manejo incorreto dos mesmos.

O uso intensivo do solo, também é um problema ambiental de suma importância. Este aliado a um manejo inadequado da água potencializa um processo natural de erosão e assoreamento (Figura 1) dos cursos de água. 
Rev. Elet. em Gestão, Educação e Tecnologia Ambiental (e-ISSN: 2236-1170)

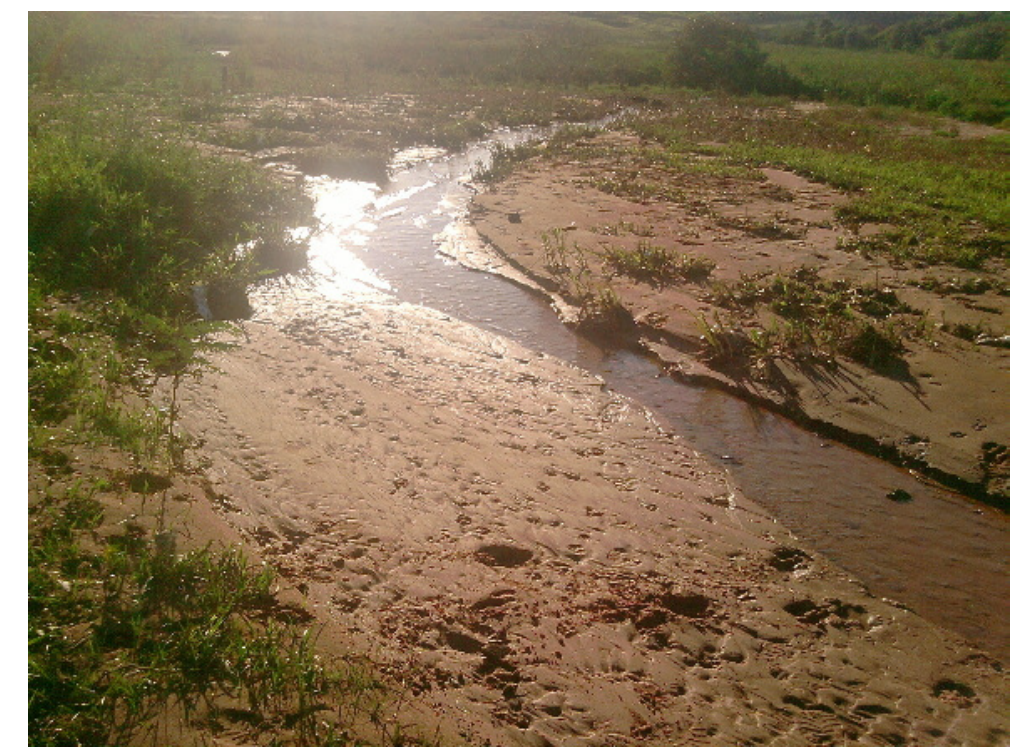

Figura 1. Assoreamento de um córrego devido à retirada da mata ciliar para, então, o usar o solo para o plantio de cana-de-açúcar.

Associado a esses problemas, está o uso de agrotóxicos de maneira inadequada. São reconhecidos os esforços no sentido de se colocarem produtos menos agressivos no mercado de agroquímicos ou até mesmo de se utilizar inseticidas ou herbicidas naturais, mas que ainda são produtos mais caros, portanto, menos consumidos.

Portanto, a presença elevada de resíduos tóxicos em alimentos, a alteração biológica, a contaminação e degradação ambiental, as intoxicações e mortes desenfreadas de seres vivos e a mudança no comportamento, surto e seleção de pragas (SAXENA, 1989), são umas das causas do uso continuado, indiscriminado e sem total planejamento de tais produtos químicos.

Um grande exemplo são os herbicidas a base de benzenaminas, os quais causam a degradação no solo, que pode ocorrer tanto em condições aeróbicas como anaeróbicas. Esta biodegradação aeróbica acontece devido às reações de desalquilação do grupo amino e em seguida a redução do grupo nitrilo.

Entretanto em condições de privação de oxigênio, há a redução seqüencial dos grupos nitro. Mas a toxicidade dos produtos químicos, utilizados pelos agricultores, varia conforme o grupo químico, sendo que os produtos compostos por organofosforados têm o maior efeito tóxico para o homem e outros mamíferos (COUTINHO et al., 2005).

Como alternativas para atenuar esses problemas utiliza-se aleloquímicos extraídos de plantas, ou seja, produtos totalmente naturais e orgânicos. Estes são mais seletivos às pragas principais da cultura, não causam danos ao ambiente e à saúde humana, possuem uma grande variação de componentes químicos. Entretanto carece de tecnologia para sua extração, e consequentemente o torna mais caro que os tradicionais compostos tóxicos.

Então vários aspectos devem ser considerados quando se pensa em irrigação, uso de agroquímicos e ação sobre o solo, tais como: a eficiência em termos do uso da água/solo; a existência de eficiência econômica; os custos ambientais desta prática, entre outras.

Se houver um plano de irrigação, ou seja, um manejo totalmente racional da mesma, ao aplicar a quantidade de água necessária às plantas no momento certo, controle de pragas de modo efetivo e menos devastador que o tradicional, é necessário que haja, deste modo, várias 
Rev. Elet. em Gestão, Educação e Tecnologia Ambiental (e-ISSN: 2236-1170)

análises ambientais como topografia, taxas de transpiração das plantas, taxas pluviométricas, etc., assim é possível atingir uma grande produção e ao mesmo tempo respeitar o ambiente.

Ao ver este panorama, percebe-se a urgência de que na agricultura reflita-se sobre seu conceito e manuseio quanto ao uso da água, pois estudos mostram que cerca de $70 \%$ dos recursos hídricos são gastos com a irrigação, que ocorre de forma desenfreada (FAO, 1998).

A demanda total de água no mundo é de apenas cerca de $11 \%$ da vazão média dos rios, $70 \%$ utilizados pelas atividades agrícolas, $20 \%$ pelas indústrias e $10 \%$ deve-se à demanda do consumo doméstico e uso municipal.

A UNESCO (2006) vai além mostrando que 90\% dos recursos hídricos do mundo são consumidos pela agricultura (Gráfico 1).

Gráfico 1. O uso da água pela indústria, agricultura e doméstico no mundo em cada região.

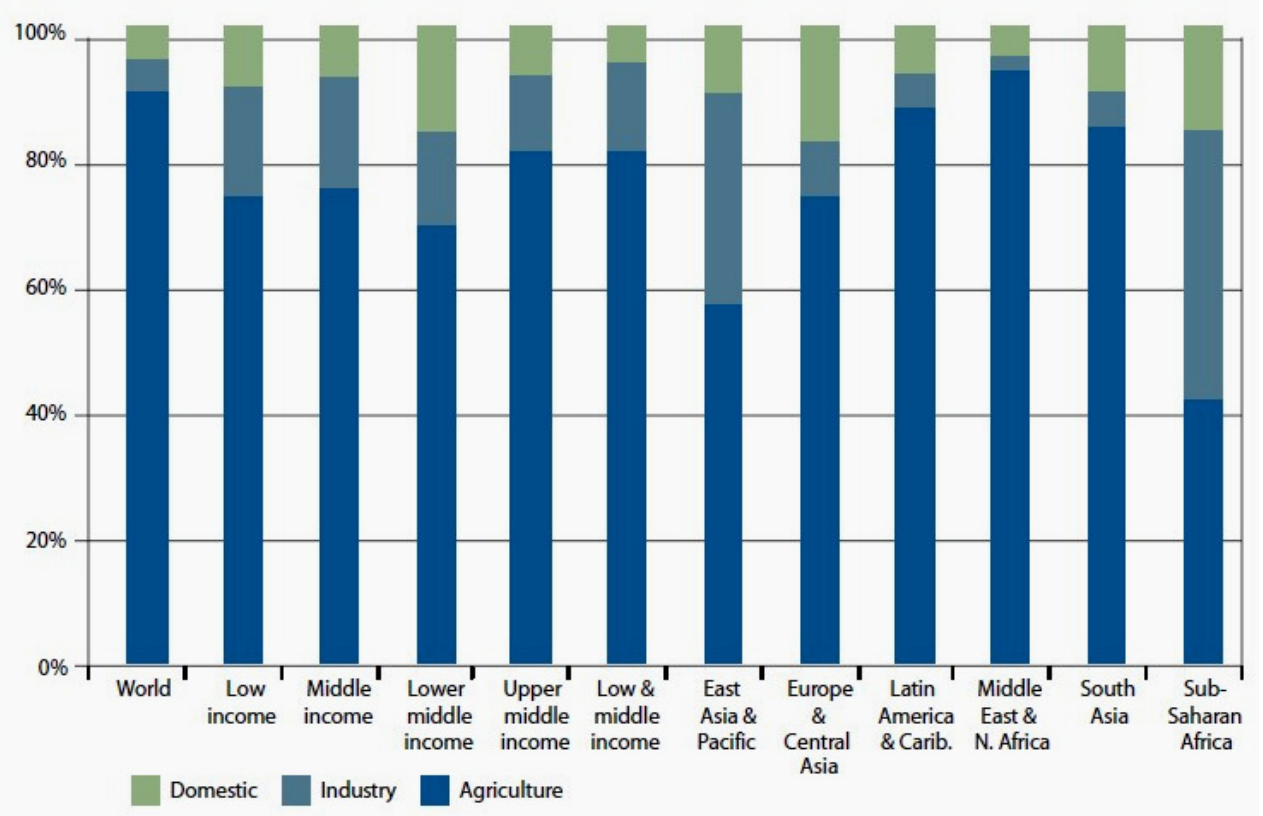

Fonte: UNESCO, 2006

As práticas inadequadas de manejo agrícola têm interferido na degradação dos solos. A degradação do solo, devido à erosão hídrica, diminui sua capacidade produtiva. Isto pode ocorrer naturalmente no ambiente, todavia com a ação contínua do homem, há uma aceleração neste processo de erosão.

É muito importante estudar e saber a importância do desgaste do solo causada pelo uso indisciplinado, pois desta forma pode-se buscar uma manutenção melhor para a produtividade e, também, a conservação ambiental, assim há a sustentabilidade do agroecossitema (PANACHUKI et al., 2006) como a AlA propõe.

Algumas práticas de manejo do solo promovem modificações em suas propriedades físicas, em grande parte na estrutura, podendo tais alterações ser permanentes ou temporárias e, ainda, influenciarem o processo erosivo. Assim, solo submetido a cultivo intensivo tem a sua estrutura original alterada, tanto em níveis de poros quanto na densidade do solo. (CARPENEDO; MIELNICZUK, 1990). 
Rev. Elet. em Gestão, Educação e Tecnologia Ambiental (e-ISSN: 2236-1170)

As práticas de monocultura, ou seja, plantar apenas uma espécie de planta numa grande região tem contribuído com a degradação ambiental. A cana-de-açúcar (Figura 2) substituiu a mata nativa e mantém-se como monocultura no estado de São Paulo por 6 décadas. Este cultivo contínuo e prolongado causa mudanças físicas no solo, principalmente sua porosidade (OLIVEIRA; VAZ; REICHARDT, 1995).

A monocultura estende-se para várias culturas como soja, pinho, eucalipto. Este exerce um grande custo ambiental para sua implantação em extensas áreas, pois devido à sua alta transpiração há enormes perdas de recursos hídricos e do solo (Figura 3). Estudos mostram que as plantações de eucalipto reduziram $227 \mathrm{~mm}$ por ano (52\%) o fluxo fluvial no mundo (BUCKUP, 2006).

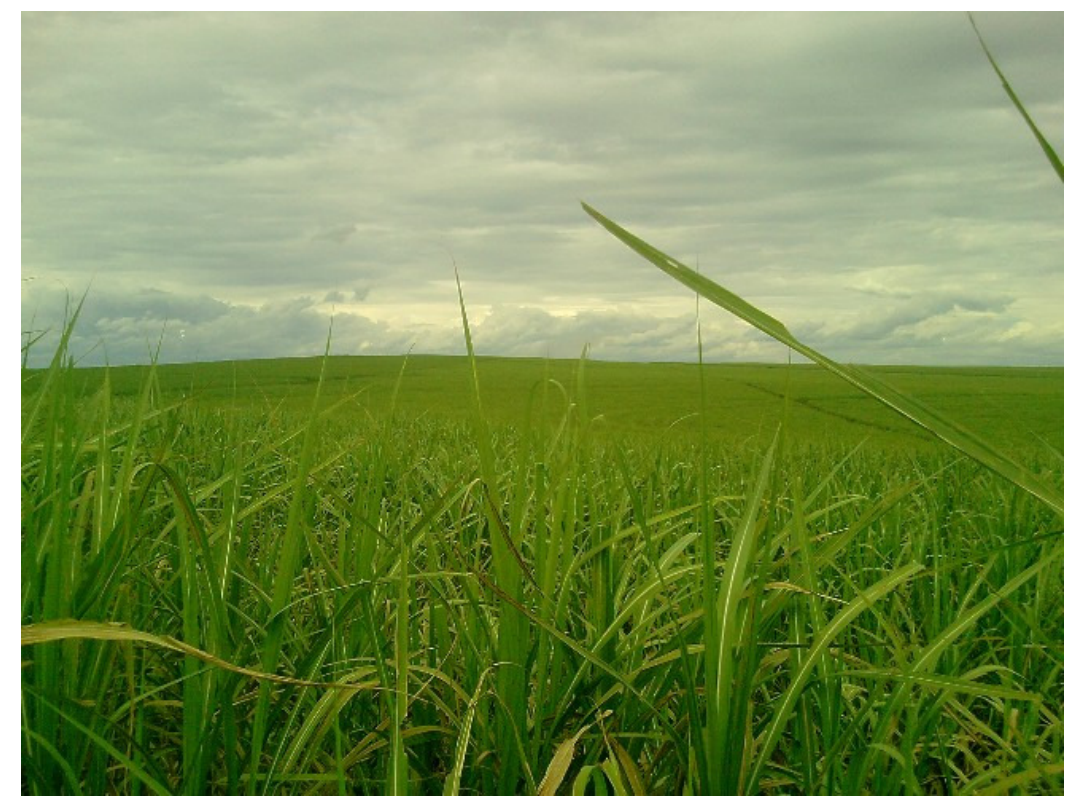

Figura 2. Monocultura de cana-de-açúcar, a qual altera as propriedades físicas do solo, devido à produção intensiva e prolongadas.

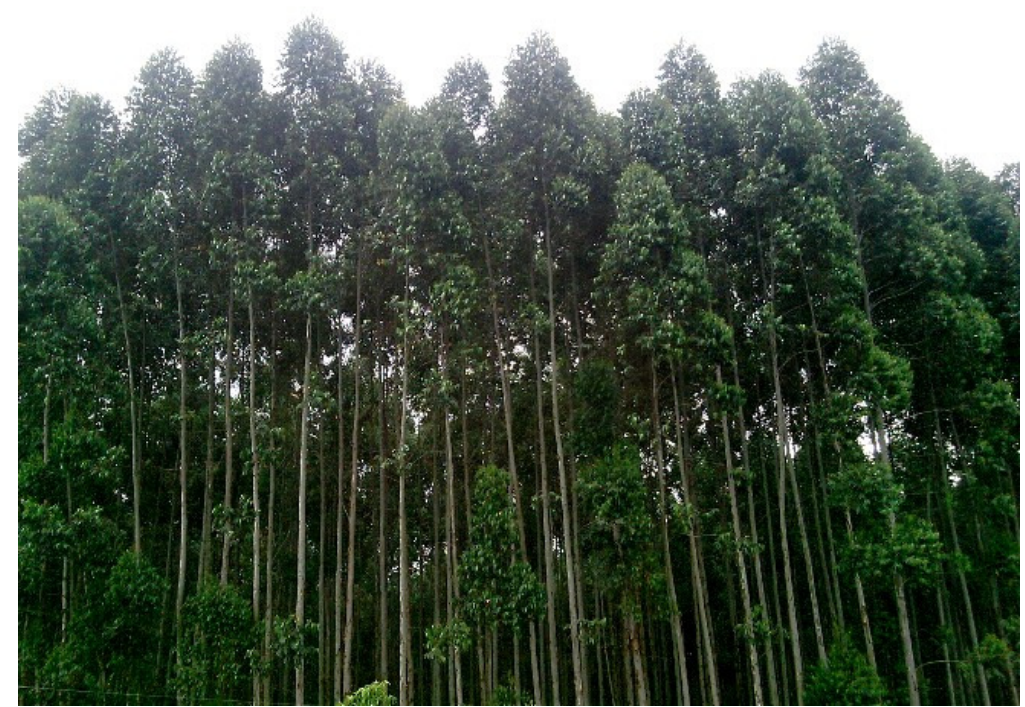

Figura 3. Monocultura de eucalipto que tem alta taxa de transpiração e, portanto, altera os recursos hídricos. 
Rev. Elet. em Gestão, Educação e Tecnologia Ambiental (e-ISSN: 2236-1170)

\section{Alternativas e remediações para a agricultura}

Ao analisar todos os problemas enfrentados pela agricultura, no quesito dos impactos sobre o meio ambiente, parece que não há soluções ou alternativas, pois estes exigem investimentos, recursos, mão de obra, etc., e, portanto, encarecem todas as alternativas, parecendo que a única solução é continuar no método tradicional, independente com o que ocorra com o ambiente.

Mas ao contrário do que parece, há várias alternativas, como já apresentadas anteriormente. Para um melhor uso da água, as pesquisas mostram que a irrigação por gotejamento (Figura 4) é altamente vantajosa em relação aos métodos tradicionais, pois tem como aplicar diretamente a água na planta e no momento certo, a operação é ágil, não necessita de tanta mão-de-obra e, principalmente, economiza água pelo uso racional.

Martins et al. (2007) verificaram que a irrigação deste tipo, em virtude destas vantagens, melhora a produção do cafeeiro, entretanto a mesma deve ser manejada adequadamente para não ocorrer perda da produção e do lucro.

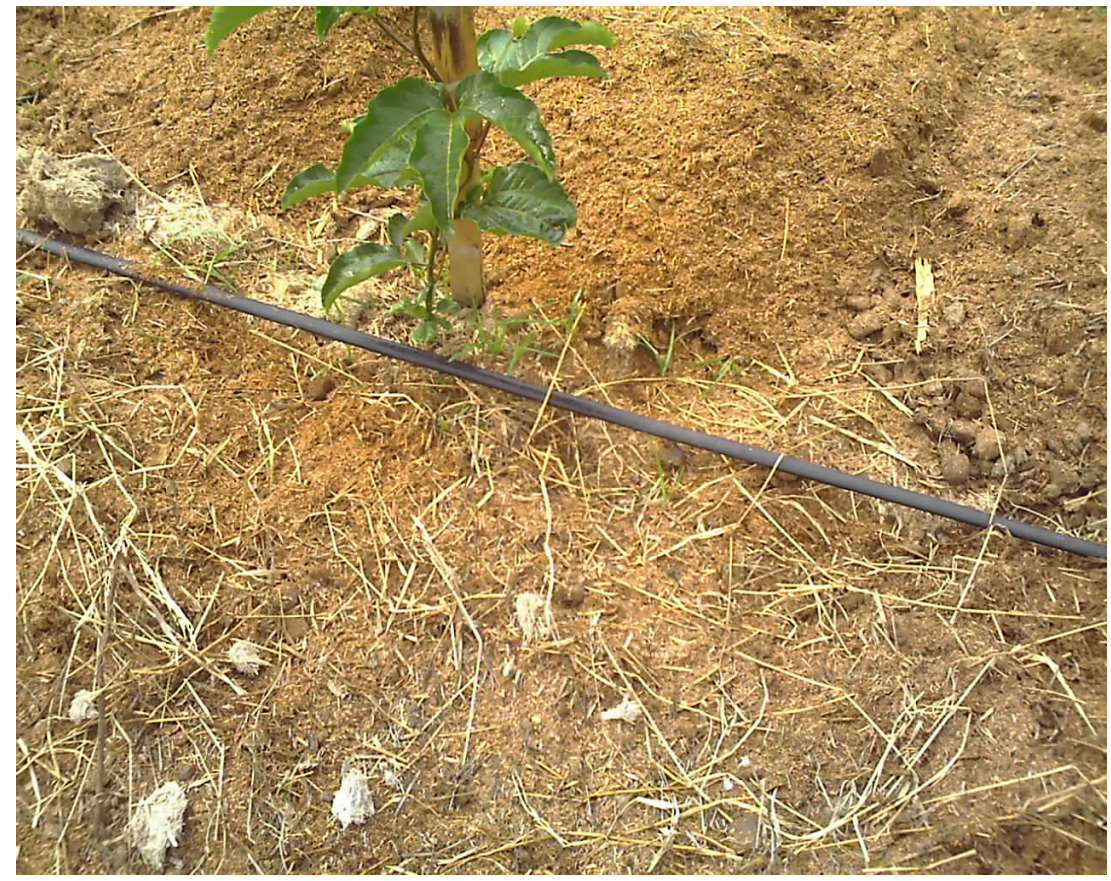

Figura 4. Exemplo de irrigação por gotejamento em maracujazeiro. A água, que sai por um furo na mangueira, é racionalmente utilizada somente para irrigar a região da raiz.

Esta irrigação localizada pode ser associada à aplicação de fertilizantes também. Essa prática, denominada fertirrigação, portanto é a aplicação de água e fertilizante simultaneamente pelo sistema de irrigação, desta forma há melhor disposição do adubo na região da raiz, fracionamento de doses e aumento da eficiência (CALDAS, 2008), portanto não há desperdício e nem mau uso da água.

Devido aos efeitos dos agrotóxicos que trazem problemas para o meio ambiente, hoje se tenta buscar alternativas para o controle de pragas e doenças com o controle biológico, ou seja, de forma natural (TANG; WEATHERSBEE; MEYER, 2002; VIEGAS JUNIOR, 2003). 


\section{Rev. Elet. em Gestão, Educação e Tecnologia Ambiental (e-ISSN: 2236-1170)}

Um dos produtos que tem chamado a atenção são os compostos retirados da Azadirachta indica (A. Juss), o nim, que é uma Meliaceae originária da Índia e tem como metabólitos secundários vários tipos de limonóides, sendo o principal a azadiractina (MORDUE; NISBET, 2000).

Este tem efeito em insetos, pestes, alterando sua alimentação, reprodução e crescimento; e efeito de repelência (MARTINEZ, 2002; MORDUE; NISBET, 2000) e possui baixa toxicidade para os predadores naturais e polinizadores, e se degrada rapidamente no ambiente (LOWERY; ISMAN, 1995; MARTINEZ, 2002). Deus (2008) concluiu "que o óleo de nim tem um grande potencial para controlar a incidência de vírus no maracujazeiro, devido à ação de repelência do óleo". Além deste composto, há vários outros em estudos.

Amadioha; Uchendu, (2003) recomendam o uso de extrato de neem para controlar Fusarium solani em frutos de tomate em armazenamento. Testes in vitro de extrato etanólico de nim, mostra sua capacidade de inibição de crescimento e desenvolvimento da antracnose da manga, Colletotrichum gloeosporioides (GREENOUGH; TUDELA, 1999). E para avaliar o efeito do nim no meio ambiente Ruch et al (1996) avaliaram o desenvolvimento de minhoca em solo com concentrações variadas de nim, notando que não houve efeito negativo sobre tais animais e, no entanto, em alta concentração ocorreu um leve acréscimo no desenvolvimento das minhocas.

Com esses resultados vimos que há alternativas para o uso de produtos tóxicos ao meio ambiente e aos seres vivos.

Para evitar o uso prolongado do solo, devido ao cultivo de uma cultura e, consequentemente o desgaste do mesmo, é necessário que haja uma rotação de culturas. Desta forma o meio ambiente pode ser conservado com suas estruturas físicas e químicas.

Entretanto Stone; Silveira (2001) diz que a rotação de culturas também pode alterar as propriedades físicas do solo, pois a intensidade da alteração de culturas é dependente do período e número de cultivo anualmente e também de quais espécies serão cultivadas.

O mesmo autor conclui o seguinte:

\footnotetext{
"A interação ano $\mathrm{x}$ sistemas de preparo do solo $\mathrm{x}$ sistemas de rotação de culturas foi significativa para todas as propriedades físicas analisadas, em todas as camadas consideradas, provavelmente em decorrência não só das variadas condições climáticas e de doenças e pragas, que condicionaram diferentes desenvolvimentos das culturas e, por conseguinte, diferentes aportes de material vegetal ao solo, mas também da variação anual nas culturas implantadas, de acordo com o esquema de rotação..."
}

Portanto é preciso muito mais estudos das consequências que a agricultura irracional traz para o meio ambiente e para a sociedade, pois na maioria das vezes focamos apenas na indústria e nas cidades e mal pensamos que no campo há um descaso com a natureza.

É necessário que haja mais fiscalização e aplicação das leis ambientais para buscar o equilíbrio entre desenvolvimento econômico e sustentabilidade ambiental. Então é preciso que a Avaliação de Impacto Ambiental saia do papel para a realidade e, então, o meio ambiente incluindo todos nós - ganhará com isto.

\section{REFERÊNCIAS BIBLIOGRÁFICAS}

AMADIOHA, A.C.; UCHENDU, P.N. Post harvest control of Tomato Fruit Rot caused by Fusarium solani with extracts of Azadirachta indica. Discovery and Innovation, v.15, n.1/2, p.83-86, 2003. 
Rev. Elet. em Gestão, Educação e Tecnologia Ambiental (e-ISSN: 2236-1170)

BOWERS, J.; HOPKINSON, P. The treatment of landscape in project appraisal:consumption and sustainability approaches. Project Appraisal, v. 9, n. 2, p. 110-118, 1994.

BRASIL. Conselho Nacional do Meio Ambiente. Resolução n.001, de 23 de janeiro de 1986. Dispõe sobre critérios básicos e diretrizes gerais para o Relatório de Impacto Ambiental RIMA. Diário Oficial [da] República Federativa do Brasil, Brasília, DF, 17 fev. 1986.

BUCKUP, L. A monocultura com eucaliptos e a sustentabilidade. Porto Alegre, março, 2006 [Documento Online]. Disponível em: <http://www.territoriosdacidadania.gov.br/port al/saf/arquivos/view/ater/artigos-e-revistas/A_Monocultura_com_Eucaliptos_e_a_Sustent abilidade_.pdf> Acesso em: 17/02/2010.

CALDAS, R. R. Característica de recipiente e densidade de planta de pepino, cultivada em substrato de fibra de coco com fertirrigação. 2008. 52f. Dissertação de Mestrado - Faculdade de Engenharia de Illha Solteira, Universidade Estadual Paulista "Júlio de Mesquita Fillho", Ilha Solteira, 2008.

CARPENEDO, V.; MIELNICZUK, J. Estado de agregados e qualidade de agregados de Latossolos Roxos, submetidos a diferentes sistemas de manejo. Revista Brasileira de Ciência do Solo, Piracicaba, v.14, n.1 p.99-105, 1990.e

COUTINHO, C. F. B. et al. Pesticidas: mecanismo de ação, degradação e toxidez. Pesticidas: Revista de Ecotoxicologia e Meio Ambiente, v. 15, p. 65-72, jan.-dez., 2005.

DEUS, R. M. Estudos da aplicação de nim no desenvolvimento das plantas, no manejo do Vírus do Endurecimento dos Frutos e na pós-colheita de frutos de maracujazeiro amarelo. 2008. 48f. Trabalho de Conclusão de Curso (Graduação) - Faculdade de Ciência, Universidade Estadual Paulista "Júlio de Mesquita Fillho", Bauru, 2008.

DOBSON, A. Green political thought. London: Routledge, 1994. 225p.

FAO. Água na agricultura. Roma: Relatório técnico, 1998, 18p.

GREENOUGH, D.R.; TUDELA, A.P. Inhibition of mango anthracnose (Colletotrichum gloeosporioides) by ethanolic leaf extracts of neem (Azadirachta indica) in the Northern Mariana Islands. Neem Proceedings, p.52-55, 1999.

LEWANDOWSKI, I.; HARDTLEIN, M.; KALTSCHMITT, M. Sustainable crop production: definition and methodological approach for assessing and implementing sustainability. Crop Sciences, v. 39, p. 184-193, 1999.

MARTELL, L. Ecology and society. Polity Press: Oxford, 1994. 240p.

MARTINEZ, S.S. (ed) O Nim - Azadirachta indica - natureza, usos múltiplos, produção. Londrina: IAPAR, 2002. $142 \mathrm{p}$.

MARTINS, C. C. et al. Manejo da irrigação por gotejamento no cafeeiro (Coffea arábica L.). Journal of Biosciesces, v. 23, n. 2, p. 61-69, Apr.-Jun. 2007.

MORDUE L, A.J.; NISBET, A.J. Azadirachtin from the neem tree Azadirachta indica: its action against insects. Anais da Sociedade Entomológica do Brasil, v.29, n.4, p.615-632, dez. 2000. 


\section{REGETAFSM \\ DE DEUS \& BAKONYI, v(7), no 7, p. 1306-1315, MAR-AGO, 2012.}

Rev. Elet. em Gestão, Educação e Tecnologia Ambiental (e-ISSN: 2236-1170)

NEHER, D. Ecological sustainability in agricultural systems: definition and measurement. Journal of Sustainable Agriculture, v. 2, n. 3, p. 51-61, 1992.

LOWERY, D.T.; ISMAN, M.B. Toxicity of neem to natural enemies of aphids. Phytoparasitica, v.23, p.297306, 1995.

OLIVEIRA, J. C. M.; VAZ, C. M. P.; REICHARDT, K. Efeito do cultivo contínuo da cana-de-açúcar em propriedades físicas de um Latossolo Vermelho Escuro. Scientia Agricola, v. 52, n. 1, p. 50-55, jan.-abr. 1995

PANACHUKI E. et al. Parâmetros físicos do solo e erosão hídrica sob chuva simulada, em área de integração agricultura-pecuária. Revista Brasileira de Engenharia Agrícola Ambiental, v.10, n.2, p.261-268, 2006.

PORTER, A. L. Technology assessment. Impact Assessment, v. 13, p. 135-151, 1995.

RODRIGUES, G. S. Conceitos ecológicos aplicados à agricultura. Revista Científica Rural, v. 4, n. 2, p. 155166, dez. 1999.

$\mathrm{RUCH}, \mathrm{B}$. et al. Summary of some environmental aspects of the neem ingredient Neem Azal and Neem Azal-T/S, 1996. In: KLEEBERG, H.; ZEBITZ, C.P.W. (eds). Proceedings of the $5^{\text {th }}$ workshop on practice oriented results on use and production of neem-ingredients and pheromones, Wetzlar, Germany, 1996, p.15-20.

SAXENA, R. C. Inseticides from Neem. In: ARNASON, J.T.; PHILOGENE, B.J.R.; MORAND, P. (Ed.) Inseticides of plant origin. Washington: ACS, 1989. cap.9, p.110-129.

STONE, L. S.; SILVEIRA, P. M. Efeitos do sistema de preparo e da rotação de culturas na porosidade e densidade do solo. Revista Brasileira de Ciência do Solo, v. 25, n. 2, p. 395-401, 2001.

TANG, Y.Q.; WEATHERSBEE III, A.A.; MAYER R.T. Effect of neem seed extract on brown citrus aphid (Homóptera: Aphididae) and its parasitoid Lysiphlebus testaceipes (Hymenoptera: Aphidiidae). Biological Control, v.31, n.1, p.172-176, feb. 2002.

TRENTO, S. M.; IRGANG, H. H.; REIS, E. M.. Efeito da rotação de culturas, da monocultura e da densidade de plantas na incidência de grãos ardidos em milho. Fitopatolia brasileira. 2002, v. 27, n. 6, p. 609-613, nov.dez. 2002.

UNESCO. Water: a shared responsibility: the united nations world water development report 2. Paris: UNESCO, 2006, p. 279.

VIEGAS JUNIOR, C. Terpenos com atividade inseticida: uma alternativa para o controle químico dos insetos. Química Nova, v. 26, n. 3, p. 390-400, 2003. 